\title{
O PAPEL DA ESCOLA INCLUSIVA COMO MEDIADORA ENTRE O ALUNO E O SABER
}

\author{
Marta Schmitd O'Connell
}

\begin{abstract}
RESUMO: É preciso considerar a escola, em todos os seus níveis de ensino, como um lugar onde cabem formas diferentes de compreender o mundo, onde conhecer é aprender a vida e seus infinitos aspectos, onde cada professor deve construir conhecimentos teóricos que lhe permitam uma visão não fragmentada do ato de educar. A prática da inclusão de alunos com necessidades educativas especiais em todos os níveis de ensino é hoje uma política educacional garantida pela legislação, tanto para a rede pública quanto privada em nosso país, apesar de serem, ainda, poucas as experiências bem sucedidas que foram cientificamente estudadas e divulgadas, gerando uma demanda para a realização de pesquisas sobre o tema. Partindo desse pressuposto, o presente trabalho propõe investigar, através de um estudo bibliográfico, como a inclusão educacional vem ocorrendo no cotidiano das Instituições de Ensino desde a Educação Infantil até ao Ensino Superior de nosso país, visando identificar os benefícios e as dificuldades referentes à implementação desta proposta educacional para a comunidade escolar como um todo.
\end{abstract}

Palavras-chave: Educação. Inclusão. Diversidade. Qualidade. 


\section{1 - INTRODUÇÃO}

Este trabalho visa esclarecer que a Educação Inclusiva é mais do que criar condições para qualquer aluno com necessidades educacionais especiais, a inclusão é um desafio que implica mudar a escola como um todo, no projeto pedagógico, na postura diante dos alunos, na filosofia, valorizar as peculiaridades de cada aluno, atender a todos, incorporar a diversidade, sem nenhum tipo de distinção.

Com isso não se trata apenas de admitir a matrícula desse aluno, isso nada mais é do que cumprir a lei. Portanto sua integração é fundamental, sendo importante o envolvimento da família e da sociedade.

A educação inclusiva é um meio privilegiado para alcançar a inclusão social, embora não seja o único. O governo e a sociedade não devem se manter alheios, pois a inclusão não se faz apenas no âmbito educativo, mas também em todo contexto social.

A inclusão, no decorrer deste processo inclusivo que é norteado por leis que visam à qualidade de ensino, deve-se apoiar em novos paradigmas educacionais desenvolvendo assim as competências e habilidade dos educandos e educadores por uma inclusão e interação abrangente na diversidade social.

A importância de discutir o tema justifica pelo fato de que, para os deficientes, ainda hoje a inclusão não é realidade em algumas escolas, sejam públicas ou privadas. A compreensão desta complexidade na realidade educacional requer um olhar inovador e tem um papel relevante frente a esses desafios.

Espera-se que este estudo conduza transformações nas instituições escolares, que ocorra mudanças de atitudes com relação aos alunos com necessidades educacionais especiais.

Mudanças que ocorram na efetivação de uma política de uma educação inclusiva, onde todos os envolvidos possam cumprir com seus deveres trabalhando a diversidade e valorizando o direito de todos à educação.

\section{2 - REFERENCIAL TEÓRICO}

Para Sassaki (1997, p. 41) inclusão é:

Um processo pelo qual a sociedade se adapta para poder incluir em seus sistemas sociais gerais pessoas com necessidades especiais e, simultaneamente, estas se preparam para assumir seus papéis na sociedade. (...) Incluir é trocar, entender, respeitar, valorizar, lutar contra exclusão, transpor barreiras que a sociedade criou para as pessoas. É oferecer o desenvolvimento da autonomia, por meio da colaboração de pensamentos e formulação de juízo de valor, de modo a poder decidir, por si mesmo, como agir nas diferentes circunstâncias da vida. 
A educação inclusiva é uma educação voltada para a cidadania global, plena, sem preconceitos e que reconhece e valoriza as diferenças.

Para o autor Gomes (2007, p. 44) a inclusão envolve:

[...] uma filosofia que valoriza diversidade de força, habilidades e necessidades [do ser humano] como natural e desejável, trazendo para cada comunidade a oportunidade de responder de forma que conduza à aprendizagem e do crescimento da comunidade como um todo, e dando a cada membro desta comunidade um papel de valor.

Percebe se que a escola trabalha baseada na defesa de princípios, valores éticos na influência dos ideais de cidadania e justiça a uma proposta que aponta a divulgação de práticas pedagógicas valorizando o aluno, individualmente, em sua maneira especial durante o processo envolvendo aprendizagem, com empenho compromisso, a comunidade escolar.

Considera se educação inclusiva através da socialização, interação e a própria construção do conhecimento. A perspectiva educacional, deverá conceder momentos (MITLER, 2003, p.25)

No campo da educação, a inclusão envolve um processo de reforma e de reestruturação das escolas como um todo, com o objetivo de assegurar que todos os alunos possam ter acesso a todas as gamas de oportunidades educacionais e sociais oferecidas pela escola.

A inclusão é um processo que inclui criatividade e atividade, se resume em "cooperação/solidariedade, respeito as diferenças, comunidade, valorização das diferenças, melhora para todos, pesquisa reflexiva (SANTOS, 1999, p. 91 ) .

Mediador é o educador responsável pela construção do conhecimento, interação , socialização do aluno com NEE, sendo a inclusão considerada uma tentativa de restaurar esse público, investigando desde os casos mais simples ao mais singelos, afinal educação de qualidade é um direito de todos.

De acordo com a autora para se realizar os desafios e metas da rede educacional deve se direcionar, focar-se nos quatro pilares da educação "aprender a conhecer, aprender a fazer, aprender a viver juntos e aprender a ser" (SANTOS, 1999, p. 92).

Porém é notado que a educação inclusiva se realiza através da socialização e aprendizado, trabalho em equipe "condizentes com a igualdade de direitos e de oportunidades educacionais para todos, em um ambiente educacional favorável” (BRASIL, 2006, p.17).

Uma educação de qualidade para todos procura vários fatores e a aceitação como a valorização das diferenças resgatando valores e o respeito ao aprender e construir conforme a Declaração de Salamanca (1994, apud BUOSI, 2012, p. 18-19):

[...] as crianças e jovens com necessidades educativas especiais devem ter acesso às escolas regulares, que a elas devem se adequar [...] elas constituem os meios mais capazes para combater as atitudes discriminatórias, construindo uma sociedade inclusiva e atingindo a educação para todos. 


\section{1 - ASPECTOS HITÓRICOS DA EDUCAÇÃO INCLUSIVA}

Os registros Históricos comprovam que vem a longo tempo a resistência à aceitação social das pessoas com deficiência e demonstram como suas vidas eram ameaçadas. Os dados revelam essa evidência entre os romanos, no início da era cristã.

Como afirma (MISÉS,1977, p. 14) sobre os antigos fatos:

Nós matamos os cães danados e touro, ferozes, degolamos ovelhas doentes, asfixiamos recém -nascidos mal constituídos mesmos as crianças se forem débeis ou anormais, nós as afogamos, não se trata de ódio, mas da razão que nos convida a separar das partes aquelas que podem corrompê-las.

Desde a antiguidade, sujeitos que apresentavam características diferenciadas eram tratados com discriminação e também com uma perspectiva discriminatória e marginalizante. Sociedades como a Espartana e a Romana eram exemplos destas práticas, ao promoveram o infanticídio e o abandono desses sujeitos.

Cabia aos anciões dessas sociedades examinarem os recém-nascidos, no sentido de os avaliarem visualmente, a fim de encontrarem defeitos que pudessem servir como motivo para as práticas descritas acima.

Ambas as sociedades abandonavam bebês em covas, em lugares distantes ou os afogavam na margem dos rios. Muitas vezes, ainda, eram atirados de desfiladeiros. Você deve estar pensando como eram cruéis estes povos, porém não se esqueça de que naquela época o "culto ao corpo" - o modelo de homem era o soldado- se fazia presente. (Fonseca,1989, p. 217), salienta que:

No passado, a sociedade desenvolveu quase sempre obstáculos à integração das pessoas deficientes. Receios, medos, superstições, frustrações, exclusões, separações etc, preenchem lamentavelmente vários exemplos históricos que vão desde Esparta à Idade Média.

A literatura da Educação Inclusiva segundo Ferreira (1994), registra a história do atendimento à pessoa com necessidades especiais no mundo ocidental, incluindo o deficiente mental, a partir de meados do século XIV, quando a questão da diferença ou a fuga do padrão considerado normal vai passar da órbita de influência da igreja para se tornar objeto da medicina.

Fonseca (1995) aponta os estudos de Jean Itard (1775-1838), na França, que foi considerado o pai da Educação Inclusiva, que investiu grande parte de sua vida na recuperação de Vitor( um menino portador de deficiência profunda). Com o menino Vitor( o menino lobo) , nasce talvez a primeira tentativa de estudar e modificar o potencial cognitivo, desenvolvendose a Itard o primeiro esforço e estudo sistemático de reabilitação de uma criança diferente.

No inicio do século $\mathrm{XX}$, mudanças significativas ocorreram a partir dos movimentos dos pais, principalmente na Europa e EUA, que buscavam melhores condições educacionais e sociais para seus filhos, nascendo, assim, as Associações de Pais e Amigos ExcepcionaisAPAES. 
Com a movimentação da família dos sujeitos com necessidades educacionais especiais, a área acadêmica também foi atingida, tendo que rever conceitos teóricos e pesquisas existentes na época que se geravam paradigmas e correntes epistemológicas diferenciadas.

Desta forma, duas visões, acerca da deficiência tornaram-se muito importantes para o desenvolvimento da Educação Especial, principalmente nos anos 40 e 50. O primeiro movimento centrava-se na visão Endógena , negando as possibilidades interventivas, visto que nesta perspectiva a deficiência encontrava-se no sujeito, algo interno que impossibilitava ao sujeito aprender, desenvolver-se, etc.

Essa visão trouxe consigo a busca por uma identificação precisa do distúrbio/deficiência , fazendo com que os testes de inteligência se propagassem. Os testes eram utilizados no sentido de delimitar as dificuldades e capacidades dos sujeitos, destacando suas incapacidades e promovendo a continuidade da discussão entre causas endógenas e exógenas.

Um segundo movimento torna-se então presente, para discutir e redefinir a perspectiva da incurabilidade do distúrbio proposta pelo movimento anterior. Nasce aqui o movimento Exógeno, destacando as questões sociais e educacionais presentes na deficiência.

Centravam, assim, suas ações nas relações sociais e culturais presentes no cotidiano dos sujeitos que apresentavam alguma deficiência. Para estes, o ingresso dos sujeitos deficientes na sociedade se fazia primordial.

\section{2 - DECLARAÇÃO DE SALAMANCA}

Devido à inquietação que a exclusão do portador de deficiência causava nos países da Europa, e também para reafirmar o direito da educação para todos, em 10 de junho de 1994. Representantes de 92 países de 25 organizações internacionais realizaram a Conferência Mundial de Educação, encontro patrocinado pelo governo espanhol e pela UNESCO, conhecida na história da Educação como a Declaração de Salamanca.

Um dos aspectos mais ressaltados durante as discussões era o modo como o sistema educacional tem atuado, levando à exclusão de uma grande parcela dos alunos. Os especialistas revelaram que a inclusão dos grupos minoritários não é uma decorrência natural do sistema de ensino, mas exatamente o oposto. $\mathrm{O}$ sistema tende a excluir os alunos diferentes, privilegiando os alunos considerados normais.

A Declaração de Salamanca partiu do seguinte pressuposto:

As escolas regulares com orientação para a educação inclusiva, são meios mais eficaz no combate às atitudes discriminatórias, propiciando condições para o desenvolvimento de comunidades integradas, base da construção da sociedade inclusiva e obtenção de uma real educação para todos. (DECLARAÇÃO DE SALAMANCA, 1994, p.09)

Teve como objetivo fundamental apontar que:

A escola inclusiva é o lugar onde todas as crianças devem aprender juntas, sempre que possível, independentemente de quaisquer dificuldades ou diferenças que elas possam ter, conhecendo ou respondendo às necessidades diversas de seus alunos, acomodando ambos os estilos e ritmos de aprendizagem 
e assegurando uma educação de qualidade a todo a através de um currículo apropriado, arranjos organizacionais, estratégias de ensino, uso de recursos e parceria com as comunidades.(DECLARAÇÃO DE SALAMANCA,1994, p.11)

A Declaração de Salamanca e a Política em Educação Especial culminou em um documento das Nações Unidas, intitulado "Regras Padrões sobre Equalizações de Oportunidades para Pessoas com Deficiência", o qual demanda que os Estados membros assegurem que a educação de pessoas com NEE seja parte integrante do sistema educacional, reafirmando o compromisso para com a Educação para Todos,ao reconhecerem a necessidade e urgência para providenciar uma educação para as crianças, jovens e adultos com necessidades educacionais especiais (NEE) dentro do sistema regular de ensino.

Proclamaram (DECLARAÇÃO DE SALAMANCA, in UNESCO, 1994, p.08) que:

- Toda criança tem direito fundamental à educação, e deve ser dada a oportunidade de atingir e manter o nível adequado de aprendizagem;

- Toda criança possui características, interesses, habilidades e necessidades de aprendizagens são únicas;

- Aqueles com necessidades educacionais especiais devem ter acesso à escola regular, que deveria acomodá-los dentro de uma Pedagogia na criança, capaz de satisfazer tais necessidades;

- Escolas regulares que possuam tal orientação inclusiva constituem os meios mais eficazes de combater atitudes discriminatórias, criando-se comunidades acolhedoras, construindo uma nova sociedade inclusiva e alcançando educação para todos; além disso, tais escolas provêm uma educação efetiva à maioria das crianças e aprimoram a eficiência e, em última instância, o custo da eficácia de todo o sistema educacional.

Também na Declaração de Salamanca fica ressaltado que os alunos com NEE deve receber apoio suplementar de que precisam para assegurar uma Educação eficaz, apostando que a Educação Inclusiva é a melhor forma de promover a solidariedade entre os alunos especiais e aqueles considerados normais.

\section{3 - INCLUSÃO E INTERAÇÃO}

A Educação Inclusiva indica que todas as pessoas com necessidades educacionais especiais sejam matriculadas nas escolas regulares, baseando-se no princípio de educação para todos.

Entretanto, devemos ser cautelosos, para não admitirmos uma ideia falsa de escola democrática. Ela será democrática, à medida que acolher a todos, integrar, educar, ensinar, respeitando as diferenças e o desenvolvimento da capacidade do aluno em aprender a aprender.

\subsection{1 - O Papel da Família}

O mundo da criança no útero materno é repleto de sensações agradáveis, de aconchego, calor e movimento, ao nascer, precisa se readaptar as novas circunstâncias, reage a luzes fortes, ruídos intensos, manipulações bruscas, que causam sentimento de angústia e desamparo. Ela sozinha não é capaz de manter-se e desenvolver-se. Depende de sua mãe para os cuidados básicos que garantem sua subsistência. 
Estes cuidados consistem, não só em alimentação, higiene, como também, carinho e proteção que contribuem, de forma significativa, para o seu desenvolvimento emocional. É nos cuidados básicos que a mãe dispensa ao recém-nascido que tem início a relação mãe/filho.

A qualidade dessa relação determina as possibilidades de um desenvolvimento global satisfatório e ajustado.

A criança precisa se sentir aceita e amada para que tenha segurança em arriscar-se nos primeiros movimentos, rumo à independência. As primeiras relações sociais que mantém á com sua mãe e sua família.

Um clima saudável proporciona bom desenvolvimento afetivo intelectual, físico e motor. Um ambiente hostil desorganiza todo processo evolutivo e a formação da personalidade.

O papel da família é fundamental como facilitador das aquisições dos padrões de postura e do movimento, na educação, no desenvolvimento da inteligência e na organização da personalidade, em todas as fazes do processo evolutivo da criança.

\subsection{2 - O Papel da Escola}

Escola é o estabelecimento público ou privado onde se ministra sistematicamente, ensino coletivo. O ensino coletivo é, portanto, pressuposto para ser "escola".

Para não ser discriminatório a ter a coletividade como público, deve ser o local onde estudam os alunos do bairro, da comunidade, independentemente de suas características individuais. Só assim a escola será o espaço adequado e privilegiado da preparação da cidadania e para o pleno desenvolvimento humano.

É urgente que a escola enfrente o desafio das diferenças e possa assim colher os benefícios de ser um local acolhedor para todos e, consequentemente ser "escola" de verdade.

A construção de uma escola de boa qualidade para todos, deve, necessariamente envolver o desenvolvimento de políticas escolares de aprimoramento profissional docente, com vistas a prepará-los pedagogicamente para trabalhar com a pluralidade sociocognitiva e experiencial dos estudantes, por meio de enriquecimento de conteúdos curriculares que provocam a igualdade, a convivência pacífica, a aprendizagem mútua, a tolerância e a justiça social.

\subsection{3 - O Papel da Sociedade.}

A inclusão social é um processo que contribui para a construção de um novo tipo de sociedade através de transformações, pequenas e grandes, no ambiente, espaços, equipamentos, aparelhos, utensílios, transporte e na mentalidade das pessoas, inclusive, do próprio portador da deficiência. E então poderemos dizer: Educação inclusiva, transporte inclusivo, lazer inclusivo, etc. Ou ainda, educação para todos, transporte para todos, lazer para todos.

A inclusão é uma proposta, um ideal. Se quisermos que a sociedade seja acessível e que dela todas as pessoas possam participar, em igualdade de oportunidades, é preciso fazer desse ideal uma realidade a cada dia. 
As ações de cada indivíduo, das instituições e dos órgãos públicos, deve ser pensada e executada no sentido de divulgar os direitos, a legislação e programar ações que garantam o acesso de todas as pessoas a todos os seus direitos. Sabe-se que mudar o contexto de uma hora para outra é impossível.

Desejar uma sociedade acessível e se empenhar pela sua construção não pode significar o impedimento de acesso das pessoas com deficiência aos serviços atualmente oferecidos, pelo contrário, deve-se manter o olhar no ideal, mas os pés na realidade.

A inclusão envolve mudanças em todas as pessoas e é um trabalho longo e desafiador. Igualdade de oportunidades é um desejo de muitas pessoas para um futuro mais inclusivo.

\subsection{4 - O Papel do Professor.}

O educador inclusivo precisa ter uma clara preocupação do caminho que terá que percorrer para alcançar seus objetivos.

Se preocupar com a sociedade mais justa e democrática, sabendo que assim ele poderá obter possibilidades e alternativas para praticar a educação.

Este educador tem que estar ciente que é de extrema importância para o desenvolvimento humano, as condições para a formação educativa, isto é essencial.

Ele tem que ser responsável para garantir ao indivíduo o direito à educação, não se preocupando apenas na transmissão de conhecimentos, mas também o afeto, o calor humano e oferecer uma escola e ensino de qualidade.

É importante se interessar e conhecer os procedimentos pedagógicos atuais para avaliar as mudanças necessárias de métodos e dos recursos específicos.

Tem que reconhecer ou procurar aprofundar na vida pessoal, no ambiente familiar destes indivíduos para que possa planejar as tarefas de ensinar, com mais profundidade e atenção, só assim irá ocorrer a transformação, por menos que seja.

Para que esta transformação se faz necessário que o educador tenha uma boa formação e procure sempre estudar e pesquisar para melhorá-la.

Este profissional deverá ter noção de ajustamento, correção e reabilitação e para isto é muito importante que promova sempre que necessário um atendimento multidisciplinar.

O educador deve ter a clara noção que, a partir do momento que escolheu lidar com a conscientização de seu sentimento de insegurança em relação ao conteúdo a ser trabalhado com os alunos.

É uma missão, uma tarefa, mas uma grande esperança e isso são o que o educador tem que ter.

Como afirma Alves (2005) os profissionais devem perceber que eles podem ser o primeiro fator da inclusão ou não dessa criança. 


\section{4 - VALORIZAR O DIREITO A EDUCAÇÃO NO CASO DE PESSOA COM NECESSIDADES ESPECIAIS.}

A Constituição Federal (1988) respalda avanços significativos em se tratando da educação escolar de pessoas com deficiência, elege como fundamentos da República a cidadania e a dignidade da pessoa humana ( $\operatorname{art} .^{\circ}$, incisos II e III), como um dos seus objetivos fundamentais, a promoção do bem de todos, sem preconceitos de origem, raça, cor, sexo, idade e quaisquer outras formas de discriminação (art.3 ${ }^{\circ}$, inciso IV ).

Garante ainda o direito à igualdade (art. $\left.5^{\circ}\right)$ e trata, no art. 205 e seguintes, do direito de todos à educação. Esse direito deve visar ao pleno desenvolvimento da pessoa, seu preparo para a cidadania e sua qualificação para o trabalho.

A Constituição também elege como um dos princípios para o ensino, a igualdade de condições de acesso e permanência na escola (art.206, inciso I), acrescenta que o dever do Estado com a educação será efetivado mediante a garantia de acesso aos níveis mais elevados de ensino, da criação artística, da pesquisa, segundo a capacidade de cada um (art.208, V).

$\mathrm{O}$ acesso a todas as séries do ensino fundamental (obrigatório) deve ser incondicionalmente garantido a todos. Entretanto critério de avaliação e de promoção tem como base o aproveitamento escolar e previsto na LDB - 1996 (art.24), dever ser reorganizados, de forma a cumprir os princípios constitucionais de igualdade de direito ao acesso e permanência na escola, bem como aos níveis mais elevados do ensino, de acordo com a capacidade de cada um.

Não adianta que todos os educandos tenham acesso a escola, sem a garantia do prosseguimento da escolaridade, de acordo com o nível que cada aluno é capaz de atingir. Ao contrário do que alguns pensam não há inclusão quando a inclusão da mesma é condicionada à matrícula

Infelizmente ainda não estamos caminhando para uma inclusão, por vários motivos tais como negligência de alguns pais, acomodação de alguns profissionais envolvidos e políticas públicas.

Toda a escola deve atender aos princípios constitucionais, não excluindo nenhuma pessoa em razão de sua origem, raça, sexo, cor, idade ou deficiência e com isso garantido a todos o direito à educação e o pleno acesso à mesma.

Para os defensores da inclusão escolar seriam indispensável que as instituições de ensino eliminassem velhos paradigmas e adotassem novos métodos e práticas de ensino adequados às diferenças individuais de um modo geral, favorecendo alternativas que buscam contemplar a diversidade presente no dia a dia escolar, além de recursos humanos e materiais, e também equipamentos especializados, para atender de um modo geral as necessidades educacionais dos aprendizes, com ou sem deficiência, mas sem discriminação (MANTOAN,1999,2001; FOREST,1985).

Não adianta o acesso de todos os educandos à escola, sem garantir o prosseguimento da escolaridade, de acordo com o nível que cada aluno é capaz de atingir. Ao contrário do que alguns pensam, não há inclusão, quando a inserção da mesma é condicionada à matrícula. 
A inclusão é uma inovação em favor de uma educação mais humana e democrática, que implica em um esforço para que as mudanças aconteçam e reestruturem as condições atuais presentes nas escolas brasileiras, em especial, as de nível básico, a qual se quer chegar, quando esta assume que as dificuldades presentes no contexto escolar não são apenas dos alunos, mas resultam em uma grande parte da maneira como o ensino é ministrado, a aprendizagem é concebida e avaliada.

É necessário mudar essas condições de ensino vigente nas maiorias das escolas, mas as mesmas enfrentam inúmeros desafios para mudar o ensino nelas ministrado para atender as especificidades dos educandos que por motivos peculiares não conseguem acompanhar os colegas da turma.

Ao aproximar os alunos entre si, tratar as disciplinas como meio de conhecer melhor o mundo e as pessoas que nos rodeiam e ter como parceiras: famílias e comunidades no cumprimento de seus objetivos, a escola estará se distinguindo em prol de um ensino de qualidade, ou seja, capaz de formar pessoas, de acordo com os padrões requeridos em uma sociedade mais evoluída e humanitária.

Em se tratando de qualidade, é bom afirmar que são espaços educativos de concentração de personalidades humanas autônomas, críticas, sobre os quais as crianças aprendem a valorizar as diferenças pela convivência com seus pares: pelos professores, pelo ensino ministrado nas salas de aula pelo clima sócio afetivo das relações estabelecidas em toda a comunidade escolar, deixando de lado as tensões competitivas.

Escolas assim concebidas não excluem ninguém de suas classes, de seus programas, de suas aulas, das atividades do convívio escolar de uma forma mais ampla. São contextos educacionais onde todos os alunos têm a possibilidade de aprender a aprender, freqüentando uma mesma turma.

Finalizando, embora possa assustar pelo grande número de mudanças e pelo teor que cada um influi no processo educacional, a inclusão é uma grande oportunidade para todos os envolvidos, sejam eles: alunos, pais e professores demonstrar suas competências, habilidades e responsabilidades diante deste novo âmbito educacional e social. Portanto, a inclusão se faz vital para melhorar as condições da escola formando gerações preparadas para viver sem preconceitos e barreiras.

\section{5 - AS ADAPTAÇÕES CURRICULARES: DE GRANDE PORTE E PEQUENO PORTE}

Seguindo diferentes níveis de atuação: nos sistemas de ensino, no projeto politicopedagógico e no planejamento do professor.

Conforme o documento Adaptações Curriculares (BRASIL, 2009, p.9) existem dois níveis de adaptações que podem ser efetivadas: as adaptações de grande porte (significativas) e as de pequeno porte (não significativas) .

De maneira geral, as adaptações curriculares de grande porte são úteis para atender à necessidade especial do aluno quando houver discrepância entre suas necessidades e as exigências do currículo regular, à medida que se amplia a complexidade das atividades 
acadêmicas, no avanço da escolarização.

As adaptações curriculares de grande porte são adaptações significativas, estratégias que compreendem ações que são da competência e atribuição político-administrativas superiores pois exigem mudanças que envolvem ações políticas, administrativas,financeiras, burocráticas. (GÓES, 2002, p. 57)

É essencial que a escola regular possibilite as mudanças que forem fundamentais para atender às necessidades do aluno.

De acordo com a Cartilha de Adaptações Curriculares de Grande Porte recomenda que tem de ter cuidados rigorosos antes de efetuar as adaptações significativas levando em questão:

- a real necessidade do aluno;

- a relação entre o nível de competência curricular do aluno e a proposta curricular regular ;

- o caráter processual do desenvolvimento humano e da aprendizagem, permanecendo aberto para subsequentes alterações nas decisões tomadas.(BRASIL, 2009, p.18)

Sendo assim a realização de tais adaptações significativas devem ter uma avaliação cautelosa do aluno, basear-se na analises do ambiente escolar e familiar do aluno,ter o envolvimento da equipe escolar durante o estudo e decisões sobre os procedimentos em cada caso,ter registrado na ficha do aluno todas as decisões e adequações efetuadas e "evitar, sempre, que as programações individuais sejam definidas, organizadas e realizadas com prejuízo para o aluno, ou seja, para o seu desempenho, promoção escolar e socialização." (BRASIL, 2006, p.21)

A Cartilha sobre adaptações alerta que evite adaptações curriculares de grande porte sem necessidades principalmente a que envolvem a retirada de conteúdos,anulação de disciplina ou de áreas curriculares complexas.(BRASIL, 2006, p.36)

Tem-se especialidades de Adaptações Curriculares de Grande Porte, definidas pelos elementos curriculares nos quais se agregam as categorias como adaptações de:

- Acesso ao currículo que é de responsabilidade da política-administrativa no que se refere a criação de condições física, ambientais e materiais para a escola e para as necessidades dos alunos, como a compra de materiais e móveis adequados á sua deficiência.Inclui também a capacitação continuada dos professores e demais profissionais;

- Adaptação de objetivos que visa a viabilidade de se retirarem objetivos básicos ou incluírem objetivos específicos, complementares e/ou alternativos tudo para beneficiar o convívio dos aluno com deficiência ao meio escolar;

- Na adaptação de tem se a escolha de tipos de conteúdos ou reestruturação da sequencia de conteúdos ou a retirada de conteúdos acompanhando as adaptações sugeridas para os objetivos educacionais. Dessa forma o docente poderá ter de trabalhar com um plano básico para classe e versões um pouco adaptadas desse plano de ensino para melhor atender as necessidades especiais dos alunos (BRASIL, 2009 p.41);

- Em método de ensino e da didática adaptar o método de ensino as necessidades de cada aluno é um procedimento fundamental na atuação profissional do educador de educação 
regular e a especial(professor do AEE (Atendimento Especializado Educacional) e demais profissionais especializados.Outra adaptação significativa é a decisão políticaadministrativa é sobre a quantidade de alunos que prevê de 25 a 30 alunos ,sendo destes um máximo de 2 com deficiência seria o ideal para uma sala. Dentro a essa categoria encontramos o papel dos profissionais que devem atuar em sintonia, tendo o professor de sala regular e professor do AEE cooperação durante o processo de planejamento,aplicação de conteúdos, avaliação e encaminhamentos para níveis posteriores de escolarização;

- A avaliação acontece por meio de um sistema continuo,permitindo reajustes iguais ao plano do professor e suas ações de ensino auxiliando as necessidades da criança em seu desenvolvimento de aprendizagem.Saber que a oportunidade de adaptar o sistema de avaliação para o aluno de acordo com sua deficiência é uma forma para avaliar a aprendizagem do educando com responsabilidade.

- Adaptação de temporalidade são ajustes no tempo de duração do aluno em uma serie/ciclo sem prejuízo quanto a sua idade, o importante é que o aluno com necessidades educacionais especiais vivencie juntamente com seus pare.( BRASIL, 2009 p.50)

As adaptações de pequeno porte não são significativas, são modificações promovidas no currículo,pelo professor, autorizando e promovendo a participação produtiva dos alunos com necessidades especiais no processo de ensino aprendizagem dentro da escola juntamente com seus colegas de sala.

Essas adaptações são decorrentes as necessidades do alunos e de responsabilidade do professor, sem depender de autorização de seus superiores nas áreas políticas administrativa.

Para que as adaptações de pequeno porte atendam as peculiaridades dos alunos o planejamento do professor deve ter : organização o espaço físico da sua sala; seleção e adaptação de materiais;planejamento das estratégias de ensino;diversificação de metodologia para ensino e avaliação e flexibilização de tempo.

O professor também tem de: favorecer a comunicabilidade e interação entre o aluno os colegas de sala e com as demais pessoas da escola; a participação em atividades em grupo ;estar presente na aquisição de equipamentos e recursos materiais específicos; utilizar de meios variados de comunicação no momento de ensino,de aprendizagem e de também no momento de avaliação e propiciar sentimentos de auto estima afastando a ideia de fracasso.

As adaptações não significativas também ocorrem nas categorias como em :

- adaptações de objetivos:que se atribuem a ajustes que o educador deve fazer nos objetivos pedagógicos que constam no seu plano de ensino,na condição de adaptá-los as peculiaridade e condições dos educandos com necessidades especiais;

- adaptações de conteúdos: "os tipos de adaptações de conteúdos podem ser a priorização de tipos de conteúdo, priorização de áreas ou unidades de conteúdo,reformulação de sequência ou a eliminação de conteúdos secundários acompanhando as adaptações propostas para os objetivos educacionais"(BRASIL, 2009, p.60).

- De acordo com a Cartilha de Pequeno Porte cabe ao professor escolher "a ordem em que o conteúdo e suas subdivisões são apresentadas"(BRASIL, 2009, p.64) e a "prioridade" também é de escolha do professor diante das necessidades especiais do aluno; 
- adaptações de método de ensino e da organização didática: é essencial o professor buscar por métodos de ensino que beneficiam as necessidades especiais de cada aluno para auxiliar na sua aprendizagem;

- adaptações do sistema de avaliação; é fundamental para ajudar as necessidades especiais o processo de avaliação por meio da modificação de técnicas ou instrumentos utilizados(BRASIL, 2009, p.71);

- adaptações de temporalidade: o educador é quem organiza o tempo das atividades conforme as necessidades especiais de seus alunos.

\section{CONSIDERAÇÕES FINAIS}

As pesquisas e estudos apresentados ao longo desse artigo mostram o quanto é complicada a vida de um portador de deficiência. Pode-se afirmar que toda essa dificuldade teve sua origem nos primórdios da história, quando a deficiência era tratada como ação maligna e sobrenatural. Desde então, as deficiências são vistas como algo ruim, encaradas com estranheza e medo. Parece inacreditável, mas essa visão negativa ainda perdura em pleno século XXI.

A educação de alunos dentro das salas de aula comuns nem sempre foi uma realidade. Como já citado nesta pesquisa, a situação só começou a mudar com a Declaração de Salamarca, que levantou questões importantes sobre a inclusão de portadores de deficiências. No Brasil foi criado já no mesmo ano, 1994, o documento Política Nacional de Educação Especial, que orienta a educação dos deficientes. Porém, ao contrário do que se esperava, esse documento não trouxe grandes avanços quanto a educação inclusiva, mas reforça o atendimento desses alunos exclusivamente no âmbito da educação especial.

Para comprovar tal fato, basta prestar atenção nas maneiras como a sociedade lida com um portador de deficiência, especialmente os portadores de deficiência intelectual. Em muitos locais as pessoas portadoras dessa deficiência são consideradas loucas, burras, ou simplesmente incapazes. É fato que muitas ideias já caíram por terra, e muito já tem sido oferecido a essas pessoas, mas é fato também que a humanidade não alcançou os níveis ideais de igualdade e respeito.

Indubitavelmente, a vida ideal do ser humano passa pela aquisição de conhecimento. A condição de ser humano está diretamente relacionada com o direito ao saber. Por isso é tão importante que todos tenham pleno acesso a educação de qualidade. Daí a importância da escola.

É dentro da escola que a criança dá seus primeiros passos em direção ao saber e cria seus primeiros laços de amizade. Os conhecimentos adquiridos e experiências vividas dentro da sala de aula serão com certeza levados para o resto da vida. Por isso, a escola "carrega o peso" de se reinventar todos os dias, a fim de atingir todas as expectativas sobre ela impostas. Isso porque o público que ela recebe é extremamente variado e heterogênio, abrangendo todos os tipos de cultura, cor, credo e situação.

Embora tudo já esteja previsto em lei, as escolas brasileiras ainda estão atreladas a métodos antigos. A escola regular há muitos anos segue formas tradicionais e conservadoras de 
ensinar. Seus métodos têm o objetivo de levar o aluno a internalizar o conteúdo curricular préestabelecido, atingindo assim o conhecimento.

Embora a legislação brasileira, pautada em todas as resoluções internacionais, tenha garantido o atendimento de alunos portadores de deficiências, a escola ainda não consegue atender bem esses alunos. Os especialistas citados aqui sugerem vários fatores como culpados, dentre eles a má formação dos professores. A legislação assegura essa formação, mas não criou meios para que ela de fato aconteça.

Por todos esses motivos, a escola inclusiva idealizada nas leis não é uma realidade. Este artigo mostrou algumas das práticas erradas que ainda são adotadas, tanto pelas escolas quanto pelos professores. Por outro lado, foram mostradas aqui também algumas práticas que, apesar de não serem tão novas assim, podem revolucionar a maneira de ensinar os portadores de deficiência. Dentre elas, podem-se destacar as salas de recursos multifuncionais e o trabalho especializado oferecido dentro dela.

Conforme as práticas realizadas nas salas de recursos foram explicadas, foi possível compreender que um aluno deficiente é perfeitamente capaz de aprender. Com os recursos e métodos corretos, este aluno aprenderá não somente os conteúdos programáticos, mas a ser cidadão crítico, livre e construtor de seu saber.

\section{BIBLIOGRAFIA}

ALVES, Denise de Oliveira et al (elaboradores). Sala de recursos multifuncionais: espaços para atendimento educacional especializado Brasília: Ministério da Educação, Secretaria de Educação Especial, 2006.

ALVES, D. de O; GOTTI, M. de O. Atendimento Educacional Especializado - Concepção, princípios e aspectos organizativos. In. BRASIL. III Seminário Nacional de formação de gestores e educadores: Ensaios Pedagógicos. MEC/SEESP: Brasília/DF, 2006.

ALVES, Fátima. Perfil do educador inclusivo. In: Inclusão: muitos olhares, vários caminhos e grande desafio. 2.ed.Rio de Janeiro: Wak, 2005,v.1,cap.8 p.59-60.

BINET e SIMON, 1905 apud STOBAUS; MOSQUERA. Educação Especial: em direção à Educação inclusiva, 2006.p.18.

BRASIL, Congresso Nacional(1988). Constituição de República Federativa do Brasil. Brasília/DF: Cetro Gráfico.

BRASIL. Lei de Diretrizes e Bases da Educação. Lei 9.394 de 20 de dezembro de 1996. Disponível em: http://www.portal.mec.gov.br/arquivos/pdf/ldb.pd. Acesso em: 09 fev. 2020.

Ministério da Educação. Educação Inclusiva: Atendimento Educacional Especializado para Deficiência Mental. Brasília, MEC/ SEESP, 2007.

. Ministério da Educação/Secretaria de Educação Especial. Resolução no 4, de 2 de Outubro de 2009. Brasília: MEC/CNE/CEB, 2009. Disponível em:

<http://peei.mec.gov.br/arquivos/Resol_4_2009_CNE_CEB.pdf>.Acesso em: 05 fev. 2020

Ministério da Educação. Secretaria de Educação Especial. Salas de Recursos Multifuncionais: espaço para atendimento educação especializado. Brasília: 2006.

BUOSI, Rosângela Bressan. Alunos com deficiência intelectual: concepções e práticas pedagógicas nas salas de recursos multifuncionais tipo I. 2112. 50 folhas. Monografia 
(Especialização em Educação: Métodos e Técnicas de Ensino). Universidade Tecnológica Federal do Paraná, Medianeira, 2012.

CORREIA, L. De M. Alunos com necessidades educativas especiais nas classes regulares. Porto: Editora Porto, 1997.

DECLARAÇÃO DE SALAMANCA. Enquadramento da ação: necessidades educativas especiais. In: Conferência Mundial sobre NEE: Acesso e qualidade - Unesco. SALAMANCA/ESPANHA: UNESCO, 1994.

FALCONI, Eliane Regina Moreno. SILVA, Natalie Aparecida Sturaro. Estratégias de trabalho para alunos com deficiência intelectual - AEE. 2017.

FREIRE, Paulo. Pedagogia da Autonomia - Saberes necessários à prática educativa. 31 Ed. São Paulo, SP. Paz e Terra (Coleção Leitura). 2005.

GLAT, Rosana; FERNANDES, Edicléia Mascarenhas. Da educação segregada à educação inclusiva: uma reflexão sobre os paradigmas atuais no contexto da educação especial brasileira. Inclusão - Revista da Educação Especial. Brasília: Ministério da Educação, Secretaria de Educação Especial, 2004. p. 35 - 39.

GOMES, A. L. e outros. Atendimento Educacional Especializado em Deficiência Mental. Brasília: MEC/SEESP, 2007.

GUIMARÃES, Arthur. Inclusão que funciona. Revista Nova Escola, Brasília, v.165, p.43,set.2003.

MAIA, Christiane Martinatti. Paradigmas da Educação Inclusiva.[et al.]- Canoas: ed. ULBRA,2008.

MANTOAN, M.T.E. Inclusão escolar: o que é? Por quê? Como fazer? 2. ed. São Paulo: Moderna, 2006.

MILANEZ, Simone Guedini Costa. OLIVEIRA, Anna Augusta Sampaio. MISQUIATTI, Andréa Regina Nunes. Org. Atendimento educacional especializado para alunos com deficiência intelectual e transtornos globais do desenvolvimento. São Paulo: Cultura Acadêmica; Marília : Oficina Universitária, 2013.

MISÉS, R. A criança Deficiente Mental - uma abordagem dinâmica. Rio de Janeiro: Zahar, 1977.

PESSOTTI, Isaías. Deficiência Mental: da superstição à ciência. São Paulo: T. A Queiroz/EDUSP, 1984.

PLETSCH, M. D. Repensando a inclusão escolar de pessoas com deficiência mental: Diretrizes políticas, currículos e práticas pedagógicas. Tese (Doutorado em Educação) Universidade do Estado do RJ - Faculdades de Educação, março de 2009.

SASSAKI, R. K. Inclusão: Construindo uma sociedade para todos.3.ed.Rio de Janeiro: WVA,2003.

WERNECK, Claudia. Você é gente? O direito de nunca ser questionado sobre o seu valor humano. Rio de Janeiro: WVA, 2003. 